\title{
Verificação das boas práticas de fabricação em panificadoras da cidade de Marabá, Pará, Brasil
}

\author{
Verification of good manufacturing practices in bakeries in the city of Marabá, Pará, Brazil
}

\author{
A. R. Maciel ${ }^{1}$; J. B. H. S. G. Oliveira ${ }^{1}$; N. M. S. Meireles ${ }^{1}$; I. S. Silva ${ }^{1}$; O. \\ M. Nascimento ${ }^{1}$; L. L. Silva ${ }^{1}$; B. S. Almeida ${ }^{2 *}$. \\ ${ }^{1}$ Graduados do curso de Tecnologia de Alimentos/Laboratório de Tecnologia de Alimentos/Universidade do Estado \\ do Pará(UEPA). Endereço: Av. Hiléia, s/n-Agrópole do INCRA - Amapá, CEP: 68502-100 - Marabá, PA - Brasil. \\ ${ }^{2}$ Docente do Departamentos de Tecnologia de Alimentos - CCNT/ Laboratório de Tecnologia de \\ Alimentos/Universidade do Estado do Pará (UEPA) Endereço: Travessa Enéas Pinheiro, 2626, Marco CEP: \\ 66095100 - Belém, PA - Brasil. \\ *bruna_alimentos@yahoo.com.br
}

(Recebido em 08 de abril de 2016; aceito em 08 de maio de 2016)

\begin{abstract}
Para garantir a qualidade dos alimentos oferecidos pelos serviços de alimentação, a Agência Nacional de Vigilância Sanitária publicou, em 21 de outubro de 2002 e 15 de setembro de 2004, as Resoluções no 216 e 275, que devem ser aplicadas a todos os estabelecimentos que processam, armazenam ou distribuem alimentos. O objetivo do trabalho foi realizar uma verificação das condições higiênico-sanitárias de duas panificadoras A e B, localizadas na cidade de Marabá-Pa. Para obtenção dos resultados foi elaborado com base na RDC no 216/2004 e 275/2002 um check-list composto pelos seguintes itens: edificação e instalações (I); equipamentos, móveis e utensílios (II); manipuladores (III); produção e transporte de alimentos (IV) e documentação (V) e as classificações foram realizadas de acordo com a porcentagem obtida em cada item analisado. Conforme os resultados verificou-se que A e B apresentaram os seguintes valores $74,36 \%$ e $51,35 \%$ de conformidade para o item I, 82,35\% e $23,53 \%$ item II, 53,85\% e $23,08 \%$ item III, $75 \%$ e $43,75 \%$ item IV e $60 \%$ e $0 \%$ item V, respectivamente. De acordo com os resultados a classificação das panificadoras analisadas variaram de bom à péssimo. Conclui-se que ambos os estabelecimentos apresentaram itens que não seguem os padrões preconizados pela legislação vigente, sendo assim, necessário a realização de cursos de capacitação aos manipuladores e reformas na estrutura física dos locais analisados, além disto, é fundamental que os órgãos de fiscalização atuem rigorosamente, e que apliquem as medidas preventivas cabíveis aos estabelecimentos que possam gerar riscos aos consumidores.
\end{abstract}

Palavras-chaves: Panificadoras, Avaliação, Qualidade.

To ensure the quality of food provided by food service, the National Health Surveillance Agency published on 21 October 2002 and 15 September 2004, the Resolutions No. 216 and 275, which must be applied to all establishments that process, store or distribute food. Given the above, the purpose of the study was to check the sanitary conditions of two bakeries A and B, located in the city of Maraba-Pa. The aim of the study was to check the sanitary conditions of two bakeries A and B, located in the city of Maraba-Pa. To obtain the results was based on the RDC No. 216/2004 and 275/2002 a check-list consisting of the following: building and facilities (I); equipment, furniture and fixtures (II); Handlers (III); production and transportation of foods (IV) and documentation (V) and the ratings were done according to the percentage obtained in each analysis item. According to the results it was found that A and B showed the following values $74.36 \%$ and $51.35 \%$ pursuant to item I, $82.35 \%$ and $23.53 \%$ item II, $53.85 \%$ and $23.08 \%$ Part III, $75 \%$ and $43.75 \%$ IR item and $60 \%$ and $0 \%$, item V, respectively. According to the results of the classification of the analyzed bakeries ranged from good to bad. It is concluded that both establishments had items that do not follow the standards set by law, therefore, necessary to carry out training courses for handlers and reforms in the physical structure of the sites analyzed, in addition, it is essential that the supervisory bodies act strictly, and to implement preventive measures applicable to establishments that may generate risks to consumers.

Keywords: Breadmaker, Evaluation, Quality. 


\section{INTRODUÇÃO}

As panificadoras são empresas que produzem e vendem pães e produtos de confeitaria. Difundiram-se no Brasil a partir da colonização, quando portugueses e espanhóis trouxeram hábitos alimentares da Europa [1]. No Brasil o consumo de pães aumentou nos últimos anos, inclusive com a adesão de produtos elaborados com outras matérias-primas, como a mandioca e milho. Atualmente o consumo per capita do brasileiro é de $32,61 \mathrm{~kg}$ de pães/ano e tende a aumentar com o aumento de renda [2].

A panificação está entre os seis maiores segmentos industriais do país, com participação de $36 \%$ na indústria de produtos alimentícios, sendo que cerca de $76 \%$ dos brasileiros consomem pães no café da manhã e $98 \%$ da população consomem outros produtos panificados [3].

Os principais problemas encontrados em panificadoras são as precárias condições higiênicosanitárias dos locais de produção, aliado ao tempo prolongado de armazenamento do trigo, bem como dos produtos processados [4]. Da mesma forma, as práticas inadequadas de higiene pessoal e de manipulação de alimentos contribuem para a contaminação destes produtos.

A qualidade deixou de ser uma vantagem competitiva e se tornou requisito fundamental para a comercialização dos produtos, atraindo assim mais clientes [5]. Um dos fatores que explica essa situação é o surgimento de novos setores alimentícios que devem obrigatoriamente oferecer aos consumidores serviços e produtos de qualidade para permanecerem ativos no mercado [1].

A Resolução n 216, de 15 de setembro de 2004, da Agência Nacional de Vigilância Sanitária - ANVISA estabelece os procedimentos de Boas Práticas em alimentação para garantir as condições higiênico-sanitárias dos alimentos preparados e direcionados ao consumo. As regras estipuladas são voltadas aos serviços de alimentação em geral e servem para auxiliar os manipuladores a prepararem, armazenarem e venderem os alimentos de forma adequada, higiênica e segura [6].

Neste contexto o presente trabalho teve como objetivo verificar as condições higiênicosanitárias de duas panificadoras localizadas na cidade de Marabá-PA.

\section{MATERIAIS E MÉTODOS}

O trabalho foi realizado em duas panificadoras localizadas no bairro Novo horizonte da cidade de Marabá-PA. Os estabelecimentos foram selecionados de forma aleatória e codificados em (A) panificadora de médio porte e (B) pequeno porte e as avaliações foram realizadas a partir do desenvolvimento e aplicação de check-list composto por 90 perguntas elaboradas com base nas resoluções RDC $n^{\circ}$ 216/2004 [6] e 275/2002 [7]. Os quesitos avaliados foram: edificação e instalações (I); equipamentos, móveis e utensílios (II); manipuladores (III); produção e transporte de alimentos (IV) e documentação (V). As opções de respostas objetivas consideradas no check-list foram sim, não e nada consta. Conforme as porcentagens obtidas os estabelecimentos foram classificados em excelente $>91 \%$; bom $\geq 70-90 \%$; regular $\geq 50-69 \%$; ruim $\geq 20$ a $49 \%$ e péssimo $<19 \%$.

\section{RESULTADOS E DISCUSSÕES}

Os resultados das condições higiênico-sanitárias das panificadoras A e B estão apresentados na Tabela 1.

Tabela 1: Resultados obtidos após a aplicação do check-list nas panificadoras A e B

\begin{tabular}{ccccc}
\hline Quesitos & \multicolumn{2}{c}{ Panificadoras } & \multicolumn{2}{c}{ Classificações } \\
\hline I & A & B & A & B \\
II & $74,36 \%$ & $51,35 \%$ & Bom & Regular \\
III & $82,35 \%$ & $23,53 \%$ & Bom & Ruim \\
IV & $53,85 \%$ & $23,08 \%$ & Regular & Ruim \\
V & $75 \%$ & $43,75 \%$ & Bom & Ruim \\
V & $60 \%$ & $0 \%$ & Regular & Péssimo \\
\hline
\end{tabular}


Os resultados mostraram que o estabelecimento A, apresentou 74,36\% de conformidade para o item edificação e instalações (I), sendo assim classificado como bom e o estabelecimento B apresentou 51,35\%, sendo este regular. A diferença dos resultados deve-se ao fato de B não possuir piso com material liso, lavável, resistente e impermeável, forros limpos, paredes em bom estado de conservação, portas e janelas com protetores de insetos e roedores. Além disto, não possuía detergente neutro disponível para a lavagem das mãos, lixeira com pedal, ambiente de trabalho desorganizado com riscos de contaminação cruzada e as instalações sanitárias eram ao lado da área de produção, sem porta e sem condições higiênicas adequadas.

No entanto, ambos os estabelecimentos utilizavam água da rede pública e não acompanhavam a qualidade da mesma através de análises físico-químicas e microbiológicas. Vale ressaltar que apenas a panificadora A realizava tratamento preventivo contra pragas.

Em relação ao item II, verificou-se 82,35\% de conformidade para panificadora A e 23,53\% para B. O estabelecimento B foi classificado como ruim, no item equipamentos, móveis e utensílios, pois os funcionários não realizavam sanitização de faças, colheres, liquidificadores, dentre outros. Não possuíam formas de pães em bom estado, as mesas e balcões não eram adequados ao processamento e não havia controle de temperatura nos sistemas de refrigeração e congelamento dos alimentos o que é um grande risco para a segurança alimentar.

A temperatura de armazenamento dos alimentos perecíveis deve ser controlada, afim de, eliminar ou reduzir o desenvolvimento de microrganismos patogênicos e deteriorados [8]. Além disto, é importante que os equipamentos e utensílios que entram em contato com os alimentos não transmitam substâncias tóxicas, odores e sabores indesejáveis, devem ser resistentes, de fácil higienização e utilizados de acordo com a sua finalidade [9].

Schimanowski; Elümke [10] verificaram que apenas $43,3 \%$ dos itens referentes a equipamentos, móveis e utensílios de panificadoras do município de Ijuí-RS estavam em conformidade com o preconizado pela legislação e Back, Oliveira e Colares [11] ao analisarem o mesmo item em panificadoras do Rio de Janeiro, observaram que $46 \%$ estavam em conformidade, sendo assim classificado como ruim.

Os resultados referentes ao item (III), para A foi 53,85\% (regular) e B 23,08\% (ruim). Verificou-se durante a avaliação que os manipuladores de ambos estabelecimentos não usavam sapados fechados e de cor clara, nem máscara durante o processamento dos alimentos. Foi verificado também a presença de adornos e esmaltes nas unhas. Além disto, os manipuladores do estabelecimento $B$, não haviam recebido curso de capacitação em boas práticas de fabricação.

Germano et al. [12] em seu estudo com padarias pertencentes a cidade de São Paulo, constaram irregularidades muito semelhantes às do presente estudo, tais como: uso de adornos, falta de proteção nos cabelos, temperaturas dos balcões de exposição fora do padrão, fluxo cruzado, entre outros.

Santi et al. [13] observaram que $82 \%$ dos vendedores ambulantes de São Carlos/SP utilizavam adornos durante a manipulação dos alimentos e Abreu et al. [14] verificaram que $58,33 \%$ dos manipuladores apresentavam fator de risco para contaminação durante a preparação de lanches pela utilização de adornos, como anéis, relógios, dentre outros. Sabe-se que os adornos devem ser removidos antes do processamento dos alimentos, pois podem ocasionar perigos de origem física e biológicos aos produtos, além de dificultarem a higienização adequada das mãos e comprometerem a qualidade dos alimentos e segurança dos consumidores [15].

Conforme o item IV, a panificadora A apresentou $75 \%$ de conformidade nos quesitos analisados e a panificadora B 43,75\%, sendo assim, classificadas em bom e ruim, respectivamente. $\mathrm{O}$ resultado encontrado no estabelecimento $\mathrm{B}$ está relacionado ao fato do mesmo não verificar o prazo de validade dos produtos adquiridos pelos fornecedores, não possuir área de armazenamento adequada, além disto, os funcionários não armazenavam corretamente os produtos alimentícios e de higienização corretamente.

Em relação a documentação o estabelecimento A apresentou 60\% de conformidade e o B $0 \%$ sendo-o classificado como péssimo, uma vez que não possuía responsável técnico, manual de boas práticas e nem alvará de funcionamento. 
Deve-se ressaltar que os estabelecimentos que trabalham com alimentos devem possuir manual de boas práticas de acordo com as normas preconizadas pela RDC n 216/2004 e os cuidados com os alimentos devem ser realizados desde o recebimento da matéria prima até a distribuição do produto.

A Lei $\mathrm{n}^{\circ}$ 6.437, de 20 de agosto de 1977 da Agencia Nacional de Vigilância Sanitária descreve que todos os estabelecimentos que trabalham com alimentos devem ser previamente licenciados pela autoridade sanitária competente estadual, distrital ou municipal, mediante a expedição de licença ou alvará. $\mathrm{O}$ não comprimento do mesmo poderá acarretar em multas ou até o fechamento do estabelecimento [16].

\section{CONCLUSÃO}

Conclui-se que as duas panificadoras avaliadas possuem quesitos que encontram-se fora dos padrões preconizados pela legislação vigente e que o estabelecimento B apresentou os resultados mais críticos, o que compromete a qualidade dos produtos fabricados. Desta forma torna-se necessário a realização de cursos de capacitação aos manipuladores de alimentos para que os mesmos possam adquirir conhecimentos básicos referentes aos riscos microbiológicos ocasionados por alimentos conservados e processados incorretamente, higiene pessoal e do ambiente de trabalho, dentre outros. Além disto, é fundamental que a estrutura física dos estabelecimentos estudados sejam reformados e padronizados conforme preconizado pela legislação vigente, e que os órgãos de fiscalização atuem rigorosamente com as medidas preventivas necessárias como interdição, suspenção ou recolhimentos dos produtos, a fim de evitar os riscos de contaminações dos alimentos, bem como a segurança dos funcionários e consumidores.

\section{REFERÊNCIAS BIBLIOGRÁFICAS}

1. Cardoso MF, Miguel V, Pereira CAM. Avaliação das condições higiênico-sanitárias e de boas práticas de fabricação em panificadoras. Alimentos e Nutrição. 2011 abr.jun: 22(2): 211-217.

2. IBGE. Sistema IBGE de Recuperação Automática - SIDRA. 2012. Disponível em: $<$ http://www.sidra.ibge.gov.br/bda/tabela/listabl.asp? $\mathrm{z}=\mathrm{t} \& \mathrm{o}=10 \& \mathrm{i}=\mathrm{P} \& \mathrm{c}=1612>$. Acesso em: 14 abr. 2016.

3. Paula-Junior FD, Francisco-Neto GJ, Ramos MP, Bandeira ALC, Silva AC. Produção mais limpa: um estudo de caso numa panificadora situada na região de Natal - RN. Bento Golcalves (RS): XXXII encontro nacional de engenharia de produção Desenvolvimento Sustentável e Responsabilidade Social: 2012.14 p.

4. Belle RL, Schuch BI, Schimanoski V, Moura D, Gonçalves E, Krause G, Lorenz RTA, Martins A, Bianquini CKC, Hübner D, Cardoso E, Koch E, Slongo J, Pereira K, Ferreira L, Budtinger T. Avaliação das práticas de fabricação em padarias: um estudo exploratório no município de Ijuí-RS. Revista Contexto e Saúde. 2004 Jul./Dez: 3(7)199-203.

5. Moro MF, Bem AR, Weise AD, Reis CCC, Schmidt CAP. Avaliação das boas práticas de fabricação em uma panificadora: Um estudo de caso. Espacios. 2015 fev: 36(09) 14-25.

6. Brasil. Ministério da Saúde, Resolução Agência de Vigilância Sanitária. Resolução no 216, de 15 de setembro de 2004. In. Diário oficial da união. Brasília, 16 de setembro de 2004. 
7. Brasil. Ministério da Saúde, Resolução Agência de Vigilância Sanitária. Resolução ${ }^{\circ}$ 275, de 21 de outubro de 2002. In. Diário oficial da união. Brasília, 23 de outubro de 2003.

8. Silva-Junior EA. Manual de Controle Higiênico-Sanitário em Serviços de Alimentação. São Paulo: Varela; 2005. 695.p

9. Brasil, Ministério da Saúde. Agência Nacional de Vigilância Sanitária. Portaria n 326, de 30 de julho de 1997. Regulamento técnico sobre as condições higiênico-sanitárias e de boas práticas de fabricação para estabelecimentos produtores/industrializadores de alimentos. Brasília, Diário Oficial da União, $1^{\circ}$ de ago. 1997.

10.Schimanowski NTL, Blümke AC. Adequação das boas práticas de fabricação em panificadoras do município de Ijuí-RS. Brazilian. Journal of Food Technology. 2011 jan/mar:14(1): 58-64, doi: 10.4260/BJFT2011140100008.14.1.58.

11.Back FS, Oliveira AG, Colares LGT. Perfil higiênico sanitário de panificadoras do município do Rio de Janeiro. Higiene Alimentar. 2007. (21)150:360.

12.Germano MIS, Boanova AB, Matté MH, Germano PML, Maldonado AG, Shimozako HJ. Padarias: a visão do consumidor sobre as condições higiênico-sanitárias. Higiene Alimentar. 2009 mai/jun: 23(172/173): 87-93.

13.Santi E, Malimpensa JA, Pereira CAM. Avaliação das condições higiênico-sanitárias do comércio ambulante, para a intervenção junto aos manipuladores de alimentos. Higiene Alimentar. 2009 maio/junho: 23(172/173): 77 - 81.

14.Abreu ES, Medeiros FS, Santos DA. Análise microbiológica de mãos de manipuladores de alimentos do município de Santo André. Univap. dez: 17(30): 30-57.

15.Rodrigues KL, Gomes JP, Conceição RCS; Brod CS; Carvalhal JB; Aleixo JAG. Condições higiênico-sanitárias no comércio ambulante de alimentos em Pelotas-RS. Ciência Tecnologia de Alimentos. 2003 set/dez: 23(3): 447 - 452.

16.BRASIL. Agencia Nacional de Vigilância Sanitária. Lei no 6.437, de 20 de agosto de 1977. Configura infrações à legislação sanitária federal, estabelece as sanções respectivas, e dá outras providências. Brasilia, diário Oficial da União 20 de agosto de 1977. 